\title{
CARTOGRAFÍA DE LA PRIMERA GUERRA CARLISTA. PLANOS DEL FRENTE DEL MAESTRAZGO DEL CAPITÁN MANFREDO FANTI (1837-1840)
}

\author{
Alfredo Faus Prieto \\ Departament de Geografia. \\ Universitat de València
}

\begin{abstract}
Resumen: Entre 1833 y 1840 tuvo lugar en España el primer episodio de las Guerras Carlistas. Los últimos enfrentamientos de esta guerra se produjeron en el llamado frente del Maestrazgo o de Aragón y Valencia, que afectaba sobre todo a las tierras del Bajo Aragón, el norte de Castellón y el sur de Cataluña. A este frente se incorporó como voluntario el modenés Manfredo Fanti en 1837, tras haberse formado como ingeniero en Italia y Francia. En ese momento, los cuerpos facultativos encargados del levantamiento y la custodia de la cartografía empleada por el ejército liberal eran su Estado Mayor General y el Real Cuerpo de Ingenieros Militares. La especialización de Fanti en las labores topográficas y cartográficas propias de toda guerra facilitó su rápida adscripción al primero de ellos, donde ejercitaría una labor logística básica que incluía el alzado de mapas y planos. En este artículo se hace una aproximación a la cartografía liberal de esta Primera Guerra Carlista y se analiza, a modo de ejemplo, el contexto militar y profesional en el que Fanti desarrolló su obra cartográfica.
\end{abstract}

Palabras clave: Reino de España, Guerras Carlistas, Frente del Maestrazgo, Manfredo Fanti, Topografía, Cartografía Militar.

\section{Cartography of the First Carlist War. Planes of the front of Maestrazgo of the captain Manfredo Fanti (1837-1840)}

Abstract: Between 1833 and 1840, the first episode of the Carlist Wars took place in Spain. The last clashes of this war took place in the so called front of the Maestrazgo or Aragon and Valencia, which it was affecting especially to the lands of the Low Aragon, Castellón's north and the south of Catalonia. To this front joined as volunteer the Italian Manfredo Fanti in 1837, after having been formed as engineer in Italy and France. In this moment, the bodies in charge of the raising and the custody of the cartography used by the liberal army were his General Staff Officer and the Military Engineers' Royal Corp. Fanti's specialization in the topographic and cartographic own labors of any war facilitated his rapid adscription to the first one of them, where he would exercise a logistic basic labor that was including the gathering of maps and planes. This article intends an approximation to the liberal cartography of this First Carlist War and analyzes, as example, the military and professional context in which Fanti developed his cartographic work.

Key words: Kingdom of Spain, Carlists Wars, Front of Maestrazgo, Manfredo Fanti, Topography, Military, Cartography.

Data de recepció: 25 d'abril de 2016 / Data d'acceptació: 23 de maig de 2016. 


\section{INTRODUCCIÓN}

Tras la muerte de Fernando VII en septiembre de 1833, estalló en España una guerra civil discontinua que dio lugar a los tres episodios bélicos de las Guerras Carlistas (1833$1840 ; 1846-1849$; y 1872-1876). Este conflicto, que venía gestándose en el marco de la crisis del Antiguo Régimen, tuvo como causa inmediata la cuestión sucesoria provocada por el propio Fernando VII al aprobar la Pragmática Sanción que declaraba como heredera al trono a su hija mayor María Isabel Luisa, nacida en 1830, en detrimento de los derechos que detentaba su hermano, el infante Carlos María Isidro. Como resultado de esta medida, en estas guerras se enfrentaron los partidarios de ambos, conocidos como isabelinos y carlistas. Al margen de los términos peyorativos que se prodigaron mutuamente, la carga ideológica que subyacía a los intereses de unos y otros hizo que también fueran denominados $l i$ berales o constitucionalistas, en el primer caso, y realistas o legitimistas, en el segundo. El ejército isabelino, por último, recibió el nombre de ejército cristino en el transcurso del primero de estos episodios, ya que durante la minoría de edad de la futura Isabel II la jefatura del estado recayó en su madre, la regente María Cristina de Borbón-Dos Sicilias.

Los combates tuvieron como escenario principal aquellas zonas de España en las que el carlismo tuvo un mayor arraigo y pudo defenderse mejor de las acometidas del ejército liberal. Este escenario incluía los territorios del norte (País Vasco, Navarra, La Rioja, Cantabria, Galicia y parte de Castilla la Vieja), del interior de Cataluña y de las montañas limítrofes entre los antiguos reinos de Aragón y Valencia. En estas zonas, la destreza a la hora de moverse sobre el terreno y la complicidad de la población, atraída por las promesas del pretendiente, hicieron que las partidas y el ejército carlista pudieran establecer un estado paralelo en muchos momentos del conflicto. Durante la Primera Guerra Carlista (la Guerra de los Siete Años), el protagonismo del frente del Norte fue casi absoluto hasta la firma del Convenio de Vergara que puso fin a las hostilidades en agosto de 1839, momento en que los enfrentamientos se concentraron en los frentes Central y del Este. En el primero de ellos, conocido también como frente del Maestrazgo o de Aragón y Valencia, la guerra se alargaría hasta junio de 1840, cuando el ejército carlista que dirigía el general Ramón Cabrera emprendió la retirada hacia el norte y cruzó el río Ebro camino de Francia.

Como puede suponerse, las necesidades logísticas inherentes a estas guerras generaron una ingente documentación histórica, desperdigada hoy por multitud de archivos. En ella se incluyen materiales cartográficos de todo tipo: mapas itinerarios descriptivos, croquis de situación, perfiles y alzados de fortificaciones, estados de fuerza, planos resumen del desarrollo estratégico de los combates, memorias de campaña, etc. Se trata de un fondo generoso y poco explotado, que presenta una doble asimetría. De un lado, frente a la abundancia de la cartografía cristina e isabelina, la generada por el bando carlista es prácticamente inexistente; de otro, se observa un gran desequilibrio entre la cartografía cristina e isabelina de las dos primeras guerras y la referida a la última de ellas, mucho más prolífica y seriada. La primera de estas asimetrías se ha justificado con el argumento de que las partidas y el ejército carlista no precisaron de la cartografía, dado su especial conocimiento del territorio en el que combatían (Caridad, 2013: 236-237); la segunda tiene su razón de ser en el hecho de que el proceso de institucionalización de la cartografía oficial española, la que dependía directamente de los organismos creados por el estado liberal, no se consolidó hasta las décadas de 1850 y 1860 (Muro et al., 1996). 
No estamos en condiciones de rebatir la primera afirmación; tampoco entra dentro de nuestras posibilidades actuales la realización de un estudio pormenorizado del conjunto de la cartografía de las Guerras Carlistas. Lo único que pretendemos aquí es empezar a cubrir un vacío de difícil justificación. Hay que tener en cuenta, en este sentido, que los escasos estudios que se han acercado a la cartografía de las Guerras Carlistas se han centrado casi exclusivamente en la tercera de ellas y, particularmente, en el Atlas publicado en 1883 por la Litografía del Depósito de la Guerra que recoge su desarrollo (Galera, 2000; Izquierdo, 2004; Rosselló, 2006: 319-321). En este artículo se hace una primera aproximación a la cartografía militar de este periodo tan convulso de la historia de España $y$, en particular, a los dos cuerpos facultativos del ejército cristino responsables de las labores topográficas y planimétricas: el Real Cuerpo de Ingenieros Militares y el Cuerpo de Estado Mayor del Ejército. Tras una introducción general a las normas cartográficas seguidas en ambos cuerpos, se concluye, a modo de ejemplo, con la obra del modenés Manfredo Fanti, ingeniero adscrito al Estado Mayor del Ejército del Centro, del que se conservan once planos levantados durante la campaña final en el frente del Maestrazgo.

Atender el contexto de realización y uso de la cartografía es un principio básico de la que se ha dado en llamar etapa posmoderna de la historia reciente de esta disciplina, iniciada por autores como David Woodward, Arthur H. Robinson y John B. Harley (Edney, 2007). La revisión metodológica que implica este enfoque contextual obliga a desbordar el marco físico del mapa, su descripción somera, y a trazar sus relaciones con el marco histórico e institucional en el que fue creado. De resultas, este tratamiento, próximo a la historia social, debería favorecer el reconocimiento del valor intrínseco de los mapas y planos, permitir la superación de la visión lineal, acumulativa y positivista que caracterizó su estudio hasta finales del siglo XX y ayudar a la recuperación de un pasado rico en contrastes que había sido reducido a una sucesión de personas y hechos puntuales (Crampton y Krygier, 2006). En el caso que nos ocupa, el acercamiento a la cartografía del ejército liberal debería ayudarnos a completar la imagen de la cartografía preinstitucional que venimos perfilando desde hace tiempo. Una cartografía de autor que pervivió en España hasta que fue sustituida, en la segunda mitad del siglo XIX, por la normalizada y estandarizada propia de la época contemporánea.

\section{LA CARTOGRAFÍA DEL EJÉRCITO LIBERAL}

Ambos contendientes fueron conscientes desde el principio de la guerra de la necesidad de dotarse de cuerpos especializados en la dirección y el desarrollo de los combates. En el caso del estado liberal, las primeras medidas fueron encaminadas a reorganizar la estructura de mando del Ejército. Así, se formó una Plana Mayor bajo el liderazgo del mariscal de campo Felipe Montes, se suprimió el sistema de Consejos (que incluía al de Guerra) y se creó el Supremo Tribunal de Guerra y Marina (R. D. de 24/3/1834). Sin embargo, tras unos primeros meses de desconcierto, los éxitos del general carlista Tomás de Zumalacárregui en el frente del Norte pusieron de manifiesto que la guerra sería más larga de lo previsto y que la teórica superioridad de las Armas Generales del ejército cristino no era suficiente para garantizar el éxito militar. Entre los problemas a los que debían enfrentarse se encontraba el escaso conocimiento que poseían del territorio en el que tenían que perseguir a las partidas carlistas. En 1834, con el conflicto mostrando su peor cara, la úni- 
ca cartografía de referencia a la que tenían acceso seguía siendo la elaborada durante la Guerra de la Independencia y sólo el Real Cuerpo de Ingenieros Militares parecía en condiciones de producir otra alternativa en la que se conjugasen el rigor científico y la utilidad militar (Alonso, 1972; 1982).

Mientras cogían vuelo las principales instituciones isabelinas de formación castrense (el Colegio Militar de Segovia, el Colegio de Artillería de Alcalá de Henares y la Escuela de Ingenieros de Guadalajara), en el verano de 1835 se anunció la creación de un Estado Mayor permanente con prerrogativas similares a las de los cuerpos facultativos (R. D. de 2/8/1835). Este Cuerpo había tenido una presencia intermitente en el ejército español desde que fuera creado a iniciativa de Joaquín Blake en 1810, circunscribiéndose sus actuaciones a breves periodos durante la Guerra de la Independencia (1810-1814) y el reinado de Fernando VII (1815; 1822-1823), antes de que éste decidiera suprimirlo definitivamente (R. O. de 23/1/1824). A lo largo de todos estos años, fueron su especialización geográfica y su labor cartográfica las que le permitieron sobrevivir a los vaivenes políticos y a las discusiones sobre si debía ser el órgano directivo del Ejército o un simple cuerpo instrumental, y sobre si debía o no estar supeditado al poder legislativo (Muro, 1991). En el contexto de la Primera Guerra Carlista, estas discusiones retrasarían la reinstauración del Cuerpo de Estado Mayor hasta principios de 1838 (R. D. de 9/1/1838), lo que no hizo sino agravar el problema cartográfico del ejército cristino.

Como consecuencia de todo ello, la cartografía del ejército liberal dependió, en según qué fases de la guerra, de los remanentes de la contienda de 1808-1814, de la actuación providencial del Real Cuerpo de Ingenieros Militares y del aporte decisivo y postrero del Cuerpo de Estado Mayor del Ejército. En las fechas que aquí nos interesan, coincidentes con los últimos años de la guerra en el frente de Aragón y Valencia, estos dos cuerpos actuaron al unísono debido a que un gran número de ingenieros militares fueron adscritos provisionalmente al Estado Mayor General del Ejército del Centro. Su actuación en materia cartográfica venía determinada por los documentos que regulaban el funcionamiento de ambos cuerpos: la Instrucción anexa al Real Decreto que dio forma en 1838 al Cuerpo de Estado Mayor del Ejército y al Depósito de la Guerra adjunto ${ }^{1}$ y la Ordenanza del Real Cuerpo de Ingenieros de 1803, que mantuvo su vigencia hasta $1839^{2}$.

La Instrucción de 1838 (Colección, 1839: 27-36) definía al Cuerpo de Estado Mayor del Ejército como el centro donde debían reunirse todos los documentos que le permitieran cumplir sus funciones como órgano director en tiempo de guerra: trabajos topográficos relacionados con las funciones atribuidas al cuerpo; itinerarios militares; memorias descriptivas en general y en particular de los cuarteles, cantones o campos en los que el ejército se estableciera; diarios de campaña; estados de fuerza del enemigo y de las divisiones y brigadas dependientes de él (situación del personal y del material a su disposición, con especial alusión a las pérdidas causadas por la guerra); informaciones sobre los hospitales y almacenes de víveres, así como sobre la composición y el espíritu público de los ejércitos; etc. (Art. 4). Además, dejaba en sus manos la prevención y el arreglo de la cartografía necesaria para el desarrollo de las operaciones militares (Art. 8), el reconoci-

\footnotetext{
1 Instrucción Aprobada por S. M. para el servicio del cuerpo de Estado Mayor à que se refiere el artículo 16 del Real decreto de organización de dicho cuerpo, 1838.

2 Ordenanza que S. M. manda observar en el servicio del Real Cuerpo de Ingenieros, 1803.
} 
miento estadístico del territorio (Arts. 9 y 14-15) y la representación en croquis de los cuarteles y campamentos levantados para facilitar el despliegue de las tropas (Arts. 1213). Según esta Instrucción, el responsable de llevar a término todas estas disposiciones era el Jefe de Estado Mayor de un ejército o división, pero podía delegarlas en los generales y brigadieres bajo sus órdenes. Para cumplirlas, unos y otros estaban autorizados a recurrir en caso de necesidad a los jefes y oficiales del Real Cuerpo de Ingenieros Militares, que quedaban adscritos de forma transitoria a la unidad correspondiente (Art. 10).

Esta Instrucción no detallaba las características formales que debía cumplir la cartografía encomendada al Cuerpo de Estado Mayor del Ejército, aspecto que sí que estaba presente en la Ordenanza del Real Cuerpo de Ingenieros (Ordenanza, 1803: 199-210). En ella se establecía el protocolo cartográfico detallado que debía observarse en campaña, siguiendo una larga tradición que buscaba la normalización de la cartografía y se remontaba hasta la Instrucción de 1757 y las Ordenanzas del Cuerpo de 1768 (Capel et al., 1988; Muro, 1993). En esta última Instrucción ${ }^{3}$, redactada a instancias del por entonces director del cuerpo unificado de artilleros e ingenieros, el conde de Aranda, se especificaba que:

-Los planos debían de ser rectangulares, más anchos que altos, y estar orientados, mediante brújula, de manera que el norte quedase en su parte superior.

-En el levantamiento de un plano podía utilizarse la escala que se desease, pero siempre tenía que estar reducida a otra en la que cada unidad del pie de Francia equivaliese a 1.000 toesas $^{4}$. Además, tenía que consignarse la igualdad de esta medida con las leguas española y francesa, la milla italiana y la vara castellana.

-Si el mapa debía de ser muy grande a causa del territorio representado, podían emplearse varias hojas siempre que se trabajasen con la misma escala.

-En todo momento debía prestarse una atención especial a las zonas fronterizas, indicando la situación de los mojones y confines que las definían.

-Los planos debían recoger fielmente y en la lengua del país toda aquella información que interesase a la defensa o a la economía nacionales: caminos, plazas fuertes, castillos, puertos, desfiladeros, campos de cultivo, lagos, ríos, etc. En los cursos de agua debía indicarse el sentido de la corriente mediante una flecha. Cuando hiciese falta (bosques, plantaciones, etc.) había que especificar a quién pertenecían estos bienes. Siempre tenían que señalarse las propiedades de la corona presentes en los núcleos urbanos.

-Era necesario dividir el espacio representado en mapas y planos en partidos y jurisdicciones, utilizando con esta finalidad una línea discontinua de puntos gruesos.

-En todas las ocasiones, la cartografía debía acompañarse de relaciones o memorias que incluyesen la descripción del territorio y los proyectos que el ingeniero-topógrafo considerase necesarios.

-Al dibujar el plano de una población, había que medir todas las líneas y ángulos, hacer uso de una escala mayor y acompañarla de otras menores referidas a los perfiles que hiciese falta levantar.

\footnotetext{
3 Instrucción para formar Mapas, ò Cartas Geograficas de Provincias, y Planos de Plazas, Puertos, Bahías, Costas, con las notas y observaciones que se previenen, Archivo General de Simancas, Valladolid, Guerra Moderna, Legajo 2990.

${ }^{4}$ La toesa era una unidad de longitud francesa equivalente a 1,949 metros o 7 pies castellanos de la época.
} 
-Era aconsejable comprobar varias veces el contenido del plano, a partir del borrador levantado en el campo.

Por su parte, en dos de los títulos del Reglamento IV de la Ordenanza de 1803 se recogían de nuevo las condiciones necesarias para el trabajo topográfico y cartográfico de los ingenieros militares. En el Título I, se indicaban los instrumentos que debían de estar disponibles en todas las direcciones del Cuerpo para el desarrollo de estas operaciones (teodolito, grafómetro, plancheta, nivel de agua, brújula con alidadas, cadena de agrimensor y reglas con subdivisiones en pies y pulgadas), así como las instrucciones que debían transmitirse a los capitanes generales e intendentes de cada región militar para que facilitasen la labor del ingeniero. A su vez, el Título II $^{5}$ :

-Precisaba que el ingeniero topógrafo quedaba en todo momento bajo la supervisión del Jefe directo del que hubiese recibido el encargo (Art. 1).

-Unificaba los caracteres de la leyenda y las escalas a utilizar en función del motivo de la representación (Arts. 2-3). En el primer caso, remitía a un formulario anexo y a los símbolos figurativos recogidos más adelante (Arts. 8-9). En el segundo, fijaba cuatro tipos de escala: de 48 leguas/pie de Burgos para la representación de los reinos; de 24 leguas/pie de Burgos para la de las provincias; de 12 leguas/pie de Burgos para la de los partidos; y de 6 leguas/pie de Burgos para la de los proyectos de obra y las operaciones militares (Art. 7) 6 . No obstante, aclaraba que en los planos y perfiles de detalle podían utilizarse otras escalas más ajustadas con el fin de que pudiesen apreciarse con mayor nitidez los elementos representados (Arts. 11-12).

-Fijaba la obligación de indicar las divisiones políticas y las fronteras del territorio en cuestión. En el caso de las jurisdicciones, los distritos o los partidos, mediante una línea de puntos gruesa y la localización exacta de mojones e hitos, al modo recogido en otro formulario anexo (Arts. 4-6). Asimismo, especificaba que debían determinarse los grados de longitud y latitud que ocupaba el mapa en toda su extensión (Art. 10) y orientarlo con ayuda de la brújula, de modo que el norte quedase en la parte superior (Arts. 11-12).

-Detallaba todas las construcciones civiles que debían recogerse en el plano (molinos, fábricas, norias, almacenes, hospitales, etc.) (Arts. 13-18) y señalaba los apartados que debía contener la memoria descriptiva adjunta: los datos propios de una topografía médica (carácter de los habitantes, salubridad pública, comunicaciones, etc.); la propiedad, extensión y calidad de los bosques; las tierras de labor; la red de aguas; los recursos mineros; etc. (Arts. 19-27).

-Enfatizaba el cuidado con el que debía redactarse dicha memoria y cuidaba de asegurar el secreto cartográfico, la copia y el archivo de los mapas y planos levantados. En este sentido, disponía que el ingeniero comisionado entregase los originales a su director jefe y que éste ordenase que se hiciesen tres copias, una para el Archivo de la Dirección de Ingenieros de la Provincia y las otras dos para ponerlas a disposición del Ingeniero General. Se prohibía expresamente la publicidad de todos estos documentos a los ingenieros, bajo amenaza de arresto (Arts. 28-29).

Equipados con estas normas, decenas de ingenieros militares del bando liberal participaron, a las órdenes de sus oficiales directos o adscritos al Cuerpo de Estado Mayor del Ejército, en las campañas de las Guerras Carlistas. En el periodo que nos ocupa, hay que

\footnotetext{
5 Su encabezamiento es: Método que debe observarse en el levantamiento de Mapas y Planos.

${ }^{6}$ La legua castellana equivalía a 4.190 metros y el pie de Burgos o castellano, a 0,278635 metros.
} 
recordar que la normativa cartográfica propia del Cuerpo de Estado Mayor del Ejército no se elaboró hasta el periodo 1847-1881 y que, por lo tanto, la fijada por el Real Cuerpo de Ingenieros Militares fue el único referente cartográfico con el que contó el ejército liberal durante la Primera Guerra Carlista. Su conocimiento y generalización fue posible gracias a la existencia de centros de formación castrense, aspecto en el que la situación de estos dos cuerpos también era distinta. El Cuerpo de Estado Mayor del Ejército no contó con un centro propio hasta que, durante la regencia de Baldomero Espartero y a iniciativa del ministro Evaristo de San Miguel, se constituyó la Escuela Especial de Estado Mayor (R. D. de 22/2/1842). Por este motivo, estuvo abierto desde el principio a todos los miembros de la Marina y las Milicias Provinciales y a los componentes del Ejército que no perteneciesen a las Armas de Artillería e Ingeniería. El Real Cuerpo de Ingenieros Militares, en cambio, contaba desde 1833 con una academia en Guadalajara, heredera de la fundada en Alcalá de Henares por el Ingeniero General José Urrutia en 1803.

Un repaso de los planes de estudios de 1803, 1816 y 1839 que se siguieron en las academias de ingenieros denota la importancia que siempre tuvieron en ellas las enseñanzas prácticas, a imitación del modelo de la École Centrale de Travaux Publiques de París (Ausejo y Velamazán, 1989). Las Matemáticas y el Dibujo Lineal, que incluyó la geometría descriptiva hasta 1839, tenían la consideración de asignaturas básicas. La segunda de ellas atendía el dibujo geométrico y topográfico, la perspectiva, la delineación y el lavado de mapas y planos. La Geografía, por su parte, era materia de tercer año en el plan de 1803, pero desapareció en el de 1816, antes de reaparecer en el de 1839 acompañada de la Geología y la Geodesia. Ni qué decir tiene que estas materias iban acompañadas de las específicas de carácter castrense (Fortificación, Táctica, Estrategia, etc.) y las propias de la ingeniería aplicada (Arquitectura, Puentes, Castrametación, etc.). Por lo que respecta a la Cartografía propiamente dicha, conocemos gran parte de los contenidos cartográficos que se impartían en la academia de Guadalajara gracias al manual redactado al efecto por el comandante Francisco de Albear y los capitanes Antonio Sánchez y Ángel Rodríguez (Albear et al., 1849).

Tras una introducción en la que se pedía la universalidad de la cartilla de signos utilizada por las distintas corporaciones siguiendo el ejemplo de Francia, la obra se centraba sobre todo en los símbolos convencionales que debían emplearse en el dibujo cartográfico. Al tratar este aspecto, los autores distinguían entre los signos propios de los objetos naturales (formas del relieve, cultivos e hidrografía) y los objetos artificiales (núcleos de población, edificios, puentes, caminos, canteras, etc.), y los clasificaban en topográficos, hidrográficos, geognósticos, corográficos, geográficos y militares, antes de proceder a su estudio detallado (Caps. III-X). En su opinión, estos signos debían usarse siempre que la escala no permitiera la representación fidedigna y directa de los objetos del territorio y los números y letras no fueran suficientes para identificarlos. Además, tenían que cumplir una serie de reglas fundamentales: ser sencillos, complementarios y poco numerosos, ajustarse a la escala y presentar varias tramas en función de si sustituían a elementos fijos o móviles (Cap. I). En el anexo final, un Atlas formado por treinta láminas recogía el conjunto de los signos convencionales propuestos.

Junto a este tema, esencial en la cartografía descriptiva propia de los ingenieros, la obra también trataba del uso del color (Cap. XI) y de la parte literaria de los mapas y planos (Cap. XII). En el primero de estos aspectos, establecía una relación directa entre la paleta de colores y los signos precedentes, siguiendo el modelo de la ya citada Instrucción 
de 1757: en el caso de las obras, el carmín debía utilizarse para las de mampostería, el siena para las de madera, el azul plomizo para las de hierro, y el bister para las de tierra; en el de las aguas, el verde claro era el indicado para las de mar, el azul de Prusia para las corrientes y el azul índigo para las estancadas; en el de las líneas, se aconsejaba el uso del bermellón para los distritos militares, el carmín claro para los partidos, el siena tostado para los pueblos, el minio para los arzobispados y el violeta para los obispados; etc. Gran importancia se concedía a la representación de las tropas en combate, que siempre debía hacerse bajo los colores del pabellón nacional respectivo (el escarlata, para las propias), al igual que los cuarteles y las posiciones decisivas; para las fortificaciones se aconsejaba el verde botella. Los buques, por último, debían identificarse gracias al estandarte real. En el caso de la escritura cartográfica, los autores reconocían la imposibilidad de detallar todas las combinaciones posibles de letras y escalas, por lo que se limitaban a señalar los usos comunes de las letras romana y bastardilla en todo tipo de cartas. Para el tamaño al que debían ajustarse en cada caso, recogían una serie de tablas muy minuciosas y remitían al lector interesado al Memorial Topographique et Militaire del Depósito de la Guerra francés.

El número de los ingenieros militares que participaron en el levantamiento de mapas y planos durante las Guerras Carlistas haciendo uso de estas normas debió de ser muy elevado. Solamente en el frente del Maestrazgo, en el periodo de 1837-1840 que aquí nos ocupa, hemos contabilizado un total de veintiséis de ellos con obra cartográfica conocida [Cuadro 1$]^{7}$. Se trata de oficiales de gran prestigio, entre los que se incluyen voluntarios y miembros de los ejércitos aliados atraídos por la causa liberal (John Kearney, Antonio Faci y Manfredo Fanti) y mandos españoles con una brillante hoja de servicios. Hasta ocho de estos últimos (Salvador Arizón, Vicente Casanovas, Pedro de Eguía, Mariano Miquel, Pedro Ortiz, Antonio Sánchez, Manuel Ubiña y Nicolás Valdés) obtuvieron la Cruz de San Fernando de Primera Clase por méritos de guerra (Carrillo, 2008). No estamos, pues, ante actores secundarios en el teatro de la contienda civil. La Ordenanza de ingenieros obligaba a que todos los ejércitos en campaña contasen con un número suficiente de ingenieros a las órdenes del Ingeniero Jefe General, a que se les diese libre acceso a los documentos depositados en el Archivo de Fortificaciones de la Inspección General de Ingenieros y a que se les proporcionase toda la ayuda que necesitasen para el desempeño de sus funciones (Reglamento V, Título $1^{\circ}$, Arts. 1 y 8 ; y Título $2^{\circ}$, Art. 5).

Podemos hacernos una idea del valor de este colectivo repasando la trayectoria profesional de Mariano Miquel i Polo (Benicarló, 1789-1854), el autor más prolífico de los relacionados aquí junto a Manfredo Fanti. Formado en el Regimiento de Infantería de Valencia, ingresó en el Real Cuerpo de Ingenieros Militares en 1810, alcanzando el cargo de comandante de la plaza de Peñíscola en 1814. Ya durante la Primera Guerra Carlista, fue ascendido a teniente coronel en 1834, ocupando el cargo de Gobernador Militar y Político de Teruel, donde llegaría a ser Comandante General. En marzo de 1836 fue nombrado Mayor General de Ingenieros del Ejército del Centro, ascendiendo en 1837 al grado de coronel. En 1839, su participación en la batalla de Chiva le valió la Cruz de San Fernando ya citada. Tras la guerra, fue Jefe de la Comandancia del Cuerpo de Ingenieros de Madrid y Director del correspondiente de Valencia, Comendador de la Real Orden de Isabel II (1843), Senador

\footnotetext{
${ }^{7}$ Entre los fondos del Centro Geográfico del Ejército (Madrid, CGE) existen decenas de planos de este mismo conflicto que aparecen registrados como anónimos y/o atribuidos genéricamente a los "ingenieros militares" o al "ejército español".
} 
por designación real (1845), Director Subinspector de las posesiones de África (1848) y Gobernador interino de Ceuta (1848-1850), entre otros cargos. En 1853, por último, obtuvo el grado de general, siendo nombrado Director Subinspector de Valencia ${ }^{8}$.

Cuadro 1. Militares con obra cartográfica conocida que participaron en el frente del Maestrazgo (1837-1840).

\begin{tabular}{|c|c|c|}
\hline Autor & Localidad/es representadas & Graduación en 1837-1840 \\
\hline Arizón Castro, Salvador & Calanda & Teniente de Ingenieros \\
\hline Belda, Francisco & Alberic, Chulilla & $\begin{array}{l}\text { Teniente Coronel de } \\
\text { Ingenieros }\end{array}$ \\
\hline Benavides, Tomás & Jaca, Huesca, Biescas & $\begin{array}{l}\text { Capitán adicto al Estado } \\
\text { Mayor }\end{array}$ \\
\hline Bruso, Manuel & Alpuente & Teniente de Ingenieros \\
\hline Cáceres Cabrillanas, Miguel & Lucena del Cid, Utiel & Capitán de Ingenieros \\
\hline Casanovas Rabanals, Vicente & Chulilla & Comandante de Ingenieros \\
\hline Castaño, Melchor del & Morella & Capitán de Artillería \\
\hline Eguía Lemonauría, Pedro de & Morella & Teniente de Ingenieros \\
\hline Faci, Antonio & Cariñena, Mequinenza & Capitán de Ingenieros \\
\hline Fanti, Manfredo & $\begin{array}{l}\text { Chiva, Tales, Sarrión, Segorbe, } \\
\text { Les Useres, Bejís, Alpuente, } \\
\text { Castielfabib, Alcalá de la Selva, } \\
\text { Aliaga, Cantavieja, La Sénia }\end{array}$ & $\begin{array}{l}\text { Capitán adicto al Estado } \\
\text { Mayor }\end{array}$ \\
\hline Gil, Juan & $\begin{array}{l}\text { Segura de los Baños, } \\
\text { Villarluengo }\end{array}$ & $\begin{array}{l}\text { Ingeniero (graduación } \\
\text { desconocida) }\end{array}$ \\
\hline Giménez de Sandoval, Crispín & Teruel, Castellote & Brigadier de Ingenieros \\
\hline Kearnay, John & Fonz, Estadilla, Barbastro & $\begin{array}{l}\text { Capitán adicto al Estado } \\
\text { Mayor }\end{array}$ \\
\hline López Gómez, Antonio & Castellote & Capitán de Ingenieros \\
\hline Mascaró, D. E. & Aliaga & Capitán de Ingenieros \\
\hline Miquel Polo, Mariano & $\begin{array}{l}\text { Huesca, Barbastro, Artasona, } \\
\text { Almodóvar del Campo, } \\
\text { Plasencia de Jalón, Ayerbe, } \\
\text { Zuera, Alquézar }\end{array}$ & Mayor General de Ingenieros \\
\hline
\end{tabular}

${ }^{8}$ De Miquel i Polo se conservan dos memorias manuscritas en el CGE: Memoria sobre la sublevación del Este del Reino de Valencia y facción de Morella (Peníscola, 19/1/1834); y Memoria dirigida al Exmo. Sr. General en Gefe del Ejército del Centro (Zaragoza, 2/5/1837). 
Cuadro 1. Militares con obra cartográfica conocida que participaron en el frente del Maestrazgo (1837-1840) (Continuación).

\begin{tabular}{|l|l|l|}
\hline \multicolumn{1}{|c|}{ Autor } & \multicolumn{1}{|c|}{ Localidad/es representadas } & \multicolumn{1}{|c|}{ Graduación en 1837-1840 } \\
\hline Moreau Durán, José & Teatro de la Guerra & $\begin{array}{l}\text { Capitán adicto al Estado } \\
\text { Mayor }\end{array}$ \\
\hline Ortiz de Pinedo, Pedro & Requena & Coronel de Ingenieros \\
\hline Peláez, Antonio & Chiva, Montán & $\begin{array}{l}\text { Ingeniero adicto al Estado } \\
\text { Mayor }\end{array}$ \\
\hline Sánchez Osorio, Antonio & Cantavieja, Segura de los Baños & $\begin{array}{l}\text { Teniente Coronel de } \\
\text { Infantería, procedente de } \\
\text { Ingenieros }\end{array}$ \\
\hline Sevilla, Gregorio & Tauste, Zaragoza & $\begin{array}{l}\text { Ingeniero (graduación } \\
\text { desconocida) }\end{array}$ \\
\hline Ubiña Sánchez, Manuel & Calatayud, Aliaga & Coronel de Ingenieros \\
\hline Ugarte Palomares, Ramón & Castellote & Coronel de Ingenieros \\
\hline Unzaga Bordona, Eusebio de & Morella & Capitán de Ingenieros \\
\hline Valdés Fernández, Nicolás & Alpuente & Coronel de Ingenieros \\
\hline Zayas Fernández, Joaquín & $\begin{array}{l}\text { Teruel, Castellote, Mas de las } \\
\text { Matas, Segura }\end{array}$ & $\begin{array}{l}\text { Coronel adicto al Estado } \\
\text { Mayor }\end{array}$ \\
\hline
\end{tabular}

Fuentes: Estado Militar de España, 1839; Servicio Geográfico del Ejército, 1974; y Carrillo, 2008.

\section{MANFREDO FANTI EN EL FRENTE DEL MAESTRAZGO}

Todos los ingenieros militares citados estuvieron presentes en los combates que condujeron al término de la Primera Guerra Carlista. El más fecundo, desde el punto de vista cartográfico, de cuantos actuaron en el frente del Maestrazgo durante la ofensiva final del ejército cristino, fue el italiano Manfredo Fanti (Fig. 1). Formado como ingeniero en Módena, llegó a España como voluntario afecto al bando liberal en 1835. Tras pasar por Cataluña, donde se empleó en los trabajos de fortificación de El Bruc (Barcelona), llegó a dicho frente a principios de 1837, integrado en el Regimiento de Cazadores de Oporto que dirigía el coronel Gaetano Borso di Carminati. Después de participar en la acción de Torreblanca y en la defensa de Castellón, fue adscrito al Estado Mayor del Ejército del Centro, donde pronto destacaría por su capacidad para el levantamiento de mapas y planos. Sería esta especialización en el trabajo topográfico y cartográfico la que le permitiría acompañar al ejército liberal en la campaña que puso fin a la guerra en las tierras del Bajo Aragón, el antiguo reino de Valencia y la comarca catalana del Baix Ebre. 
Fig. 1. Retrato de Manfredo Fanti, según una litografía de 1859 (Wikimedia Commons).

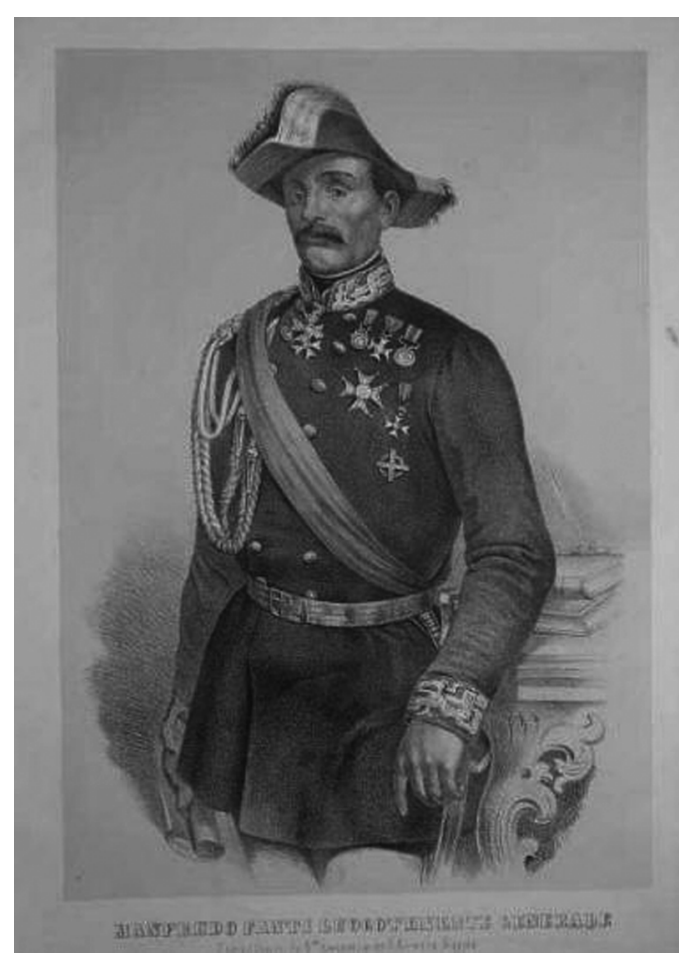

\section{El final de la Primera Guerra Carlista}

La victoria final del ejército cristino se concretó en el frente del Maestrazgo menos de un año después de la firma del Convenio de Vergara en agosto de 1839. El aislamiento en el que quedaron los últimos focos de resistencia carlista en esta zona tras el cese de la lucha en el Norte y la llegada del contingente que dirigía el general Baldomero Espartero precipitaron un desenlace que era impensable unos meses antes (Bullón, 1992; Moral, 2006). A principios de 1839, las tropas carlistas dominaban gran parte de las provincias de Valencia, Castellón, Teruel, Tarragona y Cuenca, y en las localidades de Cantavieja y Morella se estaba creando una sólida estructura militar. En la primera, elegida por Ramón Cabrera como capital de la Comandancia General bajo su mando, funcionaban desde mediados de 1837 un centro de adiestramiento de reclutas, un depósito de prisioneros, una imprenta en la que se editaba el Boletín del Ejército Real de Aragón y Valencia, talleres para la fabricación de uniformes militares, una fundición y varias fábricas de pólvora. En la segunda, mientras, se había establecido una academia para la formación de artilleros e ingenieros en la que los cadetes estudiaban, entre otras materias, dibujo topográfico (Caridad, 2013: 77-79).

El regreso de Cabrera en enero de 1837, tras participar en la marcha del general Miguel Gómez por La Mancha y Andalucía, había facilitado la reorganización del ejército carlista y la consolidación de sus posiciones en el Maestrazgo. Así, el 24 de julio de 1837, el preten- 
diente Carlos María Isidro pudo entrar con todos los honores en Cantavieja con motivo de la Expedición Real que le llevaría hasta las puertas de Madrid. La ciudad había sido conquistada por el coronel Juan Cabañero apenas tres meses antes, en lo que habría de constituir el inicio de una larga serie de encuentros favorables a las tropas carlistas. En enero de 1838 se produjo la toma de las plazas estratégicas de Morella y Benicarló y, en abril, las de Calanda, Alcorisa, Samper y Cañete. En estas plazas y en otras próximas como Alcalá de la Selva, Rubielos de Mora o Mirambel se acantonarían las fuerzas carlistas durante la primavera. El fracaso de la ofensiva lanzada sobre Morella en el mes de agosto por el general Marcelino Oráa, Jefe del Ejército del Centro, proporcionó el tiempo suficiente a los ingenieros carlistas, organizados por el capitán Antonio del Águila y el brigadier Wilhem von Rahden, para fortificar los pueblos y castillos bajo su bandera y formar una línea de guarniciones capaz de frenar la ofensiva liberal.

La primera gran derrota del ejército carlista no se produciría hasta diciembre de 1838 , cuando la partida de Domingo Forcadell fue batida en Cheste por las tropas de Juan de la Pezuela. Aunque los carlistas continuaron con su estrategia de fortificar las posiciones alcanzadas (Flix, Mora d'Ebre, Castielfabib, Beteta, etc.), el avance del ejército cristino era imparable. En junio de 1839, ya bajo la dirección del general Leopoldo O’Donell, tuvieron lugar las acciones victoriosas de Lucena, Tales y Chulilla y, entre noviembre y diciembre, el general Francisco Javier Azpiroz tomó Chelva, Torres de Castro y la propia Chulilla. En febrero de 1840 la llegada de las fuerzas comandadas por Espartero que el Convenio de Vergara había liberado en el Norte decantó definitivamente la guerra. Tras la caída de Segura de los Baños, capitularon, en una rápida sucesión, Aliaga, Bejís, Alpuente, Alcalá de la Selva, Cantavieja y Morella. El 20 de mayo, con el ejército carlista en retirada, se produjo el último encuentro en La Sénia entre O’Donell y Cabrera, antes de que éste cruzase el río Ebro por Flix. Cañete y Beteta, abandonadas por sus defensores, fueron tomadas finalmente por Azpiroz en junio.

\section{Manfredo Fanti en España}

Manfredo Fanti fue un testigo privilegiado de todos estos acontecimientos, que trasladó puntualmente al plano. Su vida, antes y después de ellos, fue la de un soldado de fortuna que encontró su razón de ser en la defensa del liberalismo en la Europa de la Restauración y el proceso de unificación que culminaría en Italia en 1870 (Carandini, 1872). Nacido en la localidad de Carpi en 1806, se formó en la Scuola dei Cadetti Pionieri de Módena, donde obtuvo la laurea en Matemáticas y el diploma en Ingeniería Civil en 1830. Aunque el título obtenido en esta academia facultaba a sus diplomados para el ejercicio de la arquitectura y la ingeniería sin necesidad de seguir la carrera militar (Riccardi, 1864), no fue el caso de Fanti. En febrero de 1831, recién graduado, se adhirió al movimiento revolucionario que encabezaría Ciro Menotti en Módena. Fracasado en primera instancia el motín, Fanti fue encarcelado junto al resto de los conjurados por orden del Francisco IV de Habsburgo-Este, archiduque de Austria y duque de Módena. Días después, en el gobierno insurreccional que ocupó el vacío de poder tras el abandono apresurado de la ciudad por parte del duque, Fanti ocupó el cargo de lugarteniente.

En el enfrentamiento posterior con las tropas austríacas que acudieron a frenar el brote revolucionario, Fanti se puso al frente de una compañía de infantería con el grado de capitán. Consumada la derrota en Rímimi, se embarcó en el puerto de Ancona con destino a 
Marsella. Una vez en Francia, fue adscrito al Dipositi d'Emigrati Italiani de Mâcon (Borgoña) y, entre 1832 y 1834, se empleó, sucesivamente, en las obras de fortificación de Lyon y Brotteaux que dirigía el general Rohault de Fleury. Completada su formación en el arte de la castrametación y tras declinar su participación en el fracasado intento de invasión del norte de Italia conocido como la Spedizione di Savoia, Fanti decidió acudir a la guerra iniciada en España entre los partidarios del absolutismo y el liberalismo. Para él, como para muchos otros italianos afines al Risorgimento que también engrosaron como voluntarios las filas isabelinas, esta guerra simbolizaba la lucha por la libertad que anhelaban para su patria (Spaggiari, 1939; Pulvirenti, 2011). Fanti debió de entender que estaba ante una oportunidad irrepetible para poner sus conocimientos técnicos al servicio de la causa liberal y, de paso, abandonar la vida sin objetivos que llevaba en Lyon.

A pesar de los obstáculos que el gobierno francés puso a la participación de los emigrados italianos en la Primera Guerra Carlista, Fanti llegó a Barcelona en julio de 1835 con un pasaporte falso a nombre de Guido Wilner. Sin embargo, no pudo enrolarse en las tropas cristinas hasta que el capitán general de Barcelona, Francisco Espoz y Mina, tuvo conocimiento de las vistas y los planos que había levantado a iniciativa propia de los terrenos del camino de Igualada en los que estaban previstas las obras de fortificación de El Bruc. Por intercesión de Espoz, Fanti fue admitido en diciembre de ese mismo año en el Quinto Batallón Franco de Cataluña con el grado de teniente, siendo destinado de manera inmediata a dichas obras. En marzo de 1836, con motivo de los combates entablados ante ellas, Fanti obtuvo la Cruz de San Fernando de Primera Clase. Terminado su cometido, se integró en el Regimiento de Cazadores de Oporto que dirigía el coronel Gaetano Borso di Carminati. Este cuerpo de mercenarios se había formado a finales de 1835 con soldados de diversos orígenes que habían participado en la guerra civil portuguesa. Entre noviembre de 1835 y mayo de 1836, cerca de dos mil setecientos de ellos fueron embarcados en Portugal con destino a Cataluña (Spaggiari, 1965).

En el segundo semestre de 1836, este regimiento participó en las acciones de Rosell y Pinell, antes de unirse al ejército del general Oráa a principios de 1837. Fanti combatió en sus filas, especializándose en labores de reconocimiento y representación cartográfica. Adscrito a la Sección Topográfica del Cuartel General de Oráa por consejo de Borso di Carminati, comenzó su ascenso en el regimiento de referencia: en julio de 1838 fue nombrado capitán y en agosto de ese mismo año obtuvo el grado de mayor. La destitución de Oráa, motivada por el fracaso del primer asalto a Morella, no impidió que Fanti continuase como auxiliar en el Cuerpo de Estado Mayor del Ejército del Centro, tanto bajo la dirección del mariscal Antonio Van Halen como bajo la del general Leopoldo O'Donell. En septiembre de 1839 , por último, abandonó el contingente de voluntarios al que pertenecía y fue admitido, con una graduación inferior, en el ejército regular español. En esa fecha fue nombrado subteniente del VI Regimiento de Infantería Ligera de Navarra, siendo ascendido al cargo de teniente apenas un mes después. Con estos empleos participaría en la ofensiva final de las tropas cristinas que aquí nos ocupa, obteniendo el grado de capitán en mayo de 1840. Una vez acabada la guerra, Fanti fue destinado a la Capitanía General de Valencia, ciudad en la que contraería matrimonio con Carlotta Tio en 1842 y tendría su primer hijo. Fue admitido definitivamente en el Cuerpo de Estado Mayor del Ejército al año siguiente 9 .

${ }^{9}$ Hoja de servicios de Manfredo Fanti, Archivo General Militar, Segovia, Sección 1a, Legajo F-88. Fanti regresó definitivamente a Italia en el verano de 1848, donde se convirtió en un héroe nacional. Entre 


\section{Planos de Manfredo Fanti}

La trayectoria descrita se refleja con fidelidad, para el periodo de la Primera Guerra Carlista, en la obra cartográfica de Fanti. Completada después de su adscripción al Cuerpo de Estado Mayor del Ejército del Centro, en ella se incluye un total de diez planos: nueve levantamientos originales y una copia realizada por Fanti a partir de una litografía del asedio a la villa y el castillo de Alpuente que obtuvo en el Depósito de la Guerra [Cuadro 2]. Este corpus de planos confirma que nuestro protagonista se encontraba inspeccionando la zona del Alto Palancia a finales de 1838 después de participar en la batalla de Caspe (Pl. 1); acompañando durante 1839 a las tropas que dirigían Leopoldo O’Donell y Francisco Javier Azpiroz (encuentros de Les Useres y Tales, Pls. 2-3); y asistiendo a la ofensiva final del ejército cristino encabezado por Baldomero Espartero en la primavera de 1840 (toma sucesiva de Bejís, Castielfabib, Aliaga, Alpuente, Alcalá de la Selva y Cantavieja, además de la acción postrera de La Sénia, Pls. 4-10). A esta decena de planos habría que añadir, finalmente, otro de la batalla de Chiva del 15 de julio de 1837, datado en 1847, que conocemos gracias a la copia que hicieron Carlos de Fidrich y Alejandro Planell del original de Fanti que estaba expuesto en la Capitanía General de Valencia (Pl. 11) ${ }^{10}$.

A pesar de tener una finalidad común, este conjunto de once planos responde a distintas tipologías de cartografía militar. En él pueden distinguirse hasta tres de las incluidas en la clasificación utilizada por Ángel Paladini en su estudio sobre la actividad cartográfica de los ingenieros militares españoles en América (1989): plano-itinerario o de longitud, planocroquis o de operaciones y plano-reconocimiento o de vistas y obras. La primera de estas tipologías respondía a la necesidad del ejército de conocer el territorio por el que debía moverse (lugares habitados, caminos, pendientes y distancias entre las poblaciones, vados de los cursos de agua, obras públicas, etc.), así como las posibles fuentes de aprovisionamiento; la segunda, a la crónica detallada de los movimientos estratégicos y las posiciones ocupadas por las tropas en asedios, encuentros y acciones de armas; la tercera, por último, a la representación de los baluartes enemigos, su localización exacta y las rutas favorables de acceso, antes o inmediatamente después de su toma.

Basta leer los títulos empleados por Fanti para inscribir sus planos en una de estas categorías, con la única excepción del croquis de Alcalá de la Selva y su castillo, de carácter mixto, que también puede ser considerado como un plano-reconocimiento. Veamos cómo se agruparían:

1842 y 1848, una vez destinado en Madrid, ascendió rápidamente en el escalafón del ejército isabelino. En octubre de 1847 obtuvo el rango de coronel y en mayo de 1848 fue condecorado con la Orden de Isabel la Católica por su participación en la Segunda Guerra Carlista.

${ }^{10}$ Fanti alude a este plano en una carta dirigida a Eduardo Fernández de San Román, fundador de la Revista Militar Española, en noviembre de 1847: “Además de varios apuntes sobre la guerra hecha por el Ejército del Centro, he hecho un plano muy extenso de la batalla de Chiva, por la extensión de casi dos leguas cuadradas" (Piva, 1914; Spaggiari, 1965: 61). La copia de Fridrich y Planell data de ese mismo año. Fanti había participado en dicha batalla, obteniendo una segunda Cruz de San Fernando de Primera Clase por méritos de guerra. 
Cuadro 2. Planos de Manfredo Fanti correspondientes al frente del Maestrazgo (1837-840).

\begin{tabular}{|c|c|c|}
\hline$N^{o}$ & Título & Año \\
\hline 1 & Bajo Aragón y Reyno de Valencia. Marcha de Sarrion á Segorbe & 1838 \\
\hline 2 & $\begin{array}{l}\text { Croquis de la gloriosa Acción ocurrida sobre los Montes de las Useras en } \\
17 \text { de Julio de } 1839\end{array}$ & 1839 \\
\hline 3 & Sitio de Tales & 1839 \\
\hline 4 & $\begin{array}{l}\text { Bexis. Reconocimiento hecho por las tropas constitucionales sobre el } \\
\text { Fuerte enemigo de Bexis en el dia } 29 \text { de Diciembre de } 1839\end{array}$ & 1840 \\
\hline 5 & $\begin{array}{l}\text { Castelfavit. Reconocimiento hecho por las tropas constitucionales sobre } \\
\text { los Fuertes enemigos de Castiel y Castelfavit en el dia } 6 \text { de Enero de } 1840\end{array}$ & 1840 \\
\hline 6 & Planos, Vistas y Perfil del Pueblo de Aliaga, su Castillo é inmediaciones & 1840 \\
\hline 7 & $\begin{array}{l}\text { Croquis de las posiciones de la } 1^{a} \text { Div. del Ejto. del Centro en el Sitio y } \\
\text { Rendición de la Villa y Castillo de Alpuente desde el } 26 \text { de Abril hasta el } \\
2 \text { de Mayo de } 1840 \text { [Copia realizada por M. Fanti de una litografía original } \\
\text { del Depósito de la Guerra] }\end{array}$ & 1840 \\
\hline 8 & Croquis de Alcalá, su Castillo y sus inmediaciones en 30 de Abril de 1840 & 1840 \\
\hline 9 & Croquis de Cantavieja y sus inmediaciones & 1840 \\
\hline 10 & Croquis de la Acción de La Cenia, ocurrida el dia 20 de Mayo de 1840 & 1840 \\
\hline 11 & $\begin{array}{l}\text { Chiva [Copia del original de M. Fanti, realizada por Carlos de Fidrich y } \\
\text { Alejandro Planell] }\end{array}$ & 1847 \\
\hline
\end{tabular}

Fuente: España. Ministerio de Defensa, Archivo del Centro Geográfico del Ejército, Madrid (CGE).

1) Plano-itinerario o de longitud (Pl. 1). En esta categoría se incluye el más antiguo de los planos firmados por Fanti, que lo realizó en noviembre de 1838 para la Capitanía General de Valencia y Murcia, poco antes de ser adscrito al Estado Mayor General del Ejército del Centro (Fig. 2). Con una escala aproximada de 1:160.000, este plano recoge los núcleos de población presentes en el camino entre las localidades de Sarrión (Teruel) y Segorbe (Castellón) y está dotado de algunas características propias: es el único de los planos de Fanti con numeración seriada ( $n^{o} 11$, junto al título), lo que da a entender que formaba parte de un atlas itinerario; el único que presenta una disposición vertical y con el norte geográfico situado en la parte inferior; el único que carece de leyenda, color y notas anexas; el único en el que la firma de Fanti está acompañada de una rúbrica alta; el único, en fin, en el que la toponimia parece reflejar el origen italiano de su autor (Vibel, Baracas, etc.). Aunque en él no se aprecia todavía la normalización impuesta por las pautas cartográficas del Real Cuerpo de Ingenieros Militares, sí que pueden verse algunas convenciones que se repetirán posteriormente en la obra de Fanti: la representación del relieve mediante hachures o líneas de sombra dibujadas en el sentido de la pendiente, la atención prioritaria a los caminos que salen de unos núcleos de población convertidos en simples figuras geométricas y la representación figurativa de los campos de cultivo próximos a los cursos de agua. 


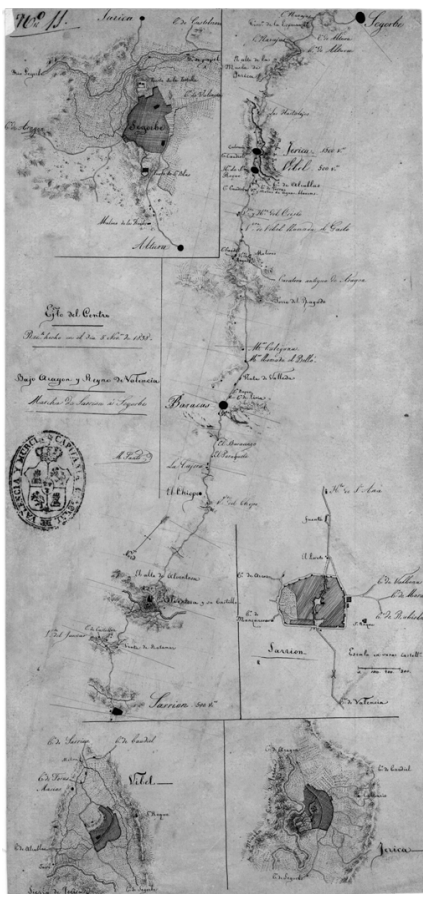

Fig. 2. M. Fanti, Marcha de Sarrión a Segorbe, 1838 (España, Ministerio de Defensa, Centro Geográfico del Ejército, Láminas históricas de la Región Valenciana, $\mathrm{n}^{\circ} 38$ ). Pl. 1, del Cuadro 2.

2) Planos-croquis o de operaciones (Pls. 2, 3, 7, 8, 9, 10 y 11). Bajo este epígrafe se clasifican siete planos de Fanti, tres de los cuales presentan rasgos propios al tratarse de una copia literal de una delineación anterior debida a otro autor (Alpuente, Pl. 7), responder a un modelo mixto de plano croquis-reconocimiento (Alcalá, Pl. 8) y estar realizado diez años después de los hechos que relata (Chiva, Pl. 11). Los cuatro restantes siguen, a su vez, dos estilos distintos. De un lado, los planos de Les Useres y Tales (Pls. 2, 3) (Fig. 3), carentes casi por completo de color, con leyenda de doble entrada (para las partes militar y topográfica) y notas anexas; de otro, los planos de Cantavieja y La Sénia (Pls. 9, 10) (Fig. 4), dotados de color, con leyendas simples y complementos muy costosos (una vista figurativa al dorso, en el primer caso, y una versión impresa del Depósito de la Guerra, en el segundo). Estas diferencias pueden atribuirse al diferente contexto en el que se realizaron: los dos primeros fueron levantados en 1839, en las condiciones precarias propias de un ejército con un Estado Mayor General móvil que debía atender a las constantes provocaciones del bando carlista, mientras que los dos restantes datan de 1840, cuando, coincidiendo con el avance imparable de las tropas constitucionales, la labor cartográfica debió de ser más agradecida. A pesar de estas diferencias, podemos encontrar en ellos varios elementos comunes ${ }^{11}$ :

${ }^{11}$ También hay otros elementos que se salen de la norma y conviene recoger aquí: la escala del plano de Les Useres viene expresada en horas de camino; la parte literaria está completamente ausente de la representación pictórica en el de Cantavieja; y el plano de La Sénia impreso lleva la firma de un desconocido Teodoro Pizarro (¿grabador?, ¿editor?, ¿mando militar?). 
Fig. 3. M. Fanti, Sitio de Tales, 1839 (España, Ministerio de Defensa, Centro Geográfico del Ejército, Láminas históricas de la Región Valenciana, $\mathrm{n}^{\circ}$ 102). Pl. 3 del Cuadro 2.
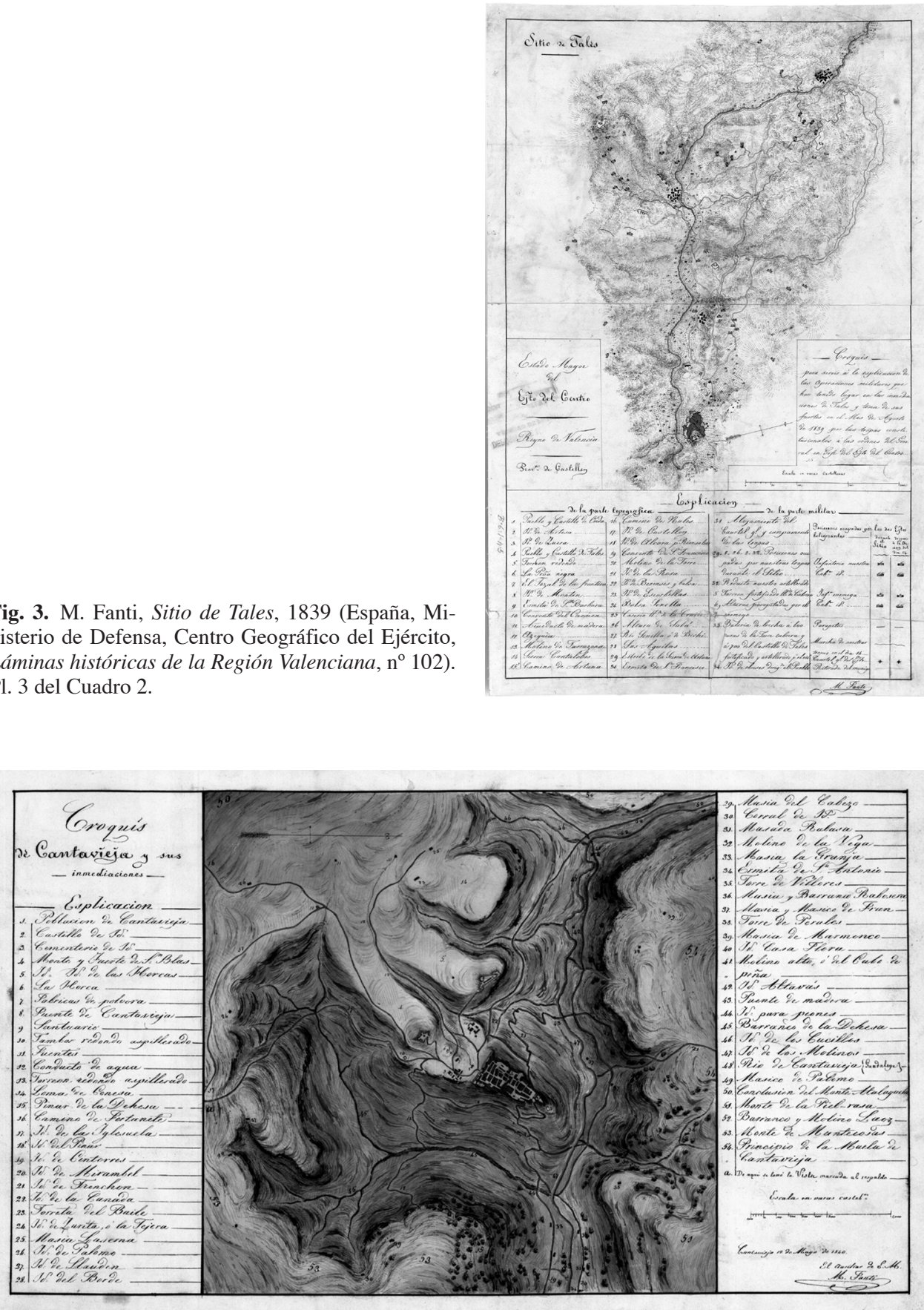

Fig. 4. M. Fanti, Croquis de Cantavieja y sus inmediaciones, 1840 (España, Ministerio de Defensa, Centro Geográfico del Ejército, Mapas y Planos Históricos de Teruel, nº 232). Pl. 9 del Cuadro 2. 
a) Datación: fechas detalladas de las acciones representadas y del momento de la delineación, que pueden encontrarse en el mismo título (Les Useres), notas anexas (Tales) o junto a la firma de Fanti (Cantavieja, La Sénia).

b) Leyenda: las entradas incluyen números, letras y símbolos gráficos. Entre estos últimos destacan los rectángulos bicolores coronados con banderolas que indican las posiciones respectivas de las tropas en combate (negro con verde, azul o púrpura, en el caso de las cristinas; negro con amarillo, marrón o gris, en el de las carlistas; una banderola para el arma de Infantería; y dos para la de Caballería); y las líneas de color que se utilizan para localizar los parapetos de piedra o las rutas de ataque y huida seguidas por los litigantes.

c) Escala: de carácter gráfico, casi siempre viene expresada en varas castellanas. Sus valores aproximados oscilan entre el 1:40.000 del plano de Les Useres y el 1:2.500 del de Tales.

d) Representación del relieve: tomando como referencia los cursos de agua y la red de caminos, los planos prestan una especial atención a la distribución de una orografía que, sin embargo, carece de altimetría y no siempre va acompañada de toponimia. El sistema de hachures o normales es el habitual a la hora de representarla, dado que las curvas de nivel no se generalizarían hasta mediados del siglo XIX. Las cumbres se dejan en claro, mientras que las líneas de sombra suelen seguir el sentido de la pendiente.

3) Planos-reconocimiento o de vistas y obras (Pls. 4, 5, 6 y 8). En este apartado se incluyen los planos más elaborados y complejos de Fanti (Figs. 5-6). Si los anteriores respondían a apuntes de campo sobreimpuestos a la cartografía topográfica preexistente, estos debieron de ser realizados completamente en estudio. De hecho, su representación no parece responder a un único momento: el plano de Bejís (Pl. 4), por ejemplo, está datado el $1 / 2 / 1840$, pero recoge el reconocimiento hecho el 29/12/1839 y los movimientos de tropas del mes de junio de 1840, que fueron añadidos con posterioridad según una nota anexa. La suma complejidad de estos planos hace que sobre el lienzo de cada uno de ellos se distribuyan, en un alarde compositivo, entre cinco y ocho elementos con recuadro propio. Además de la obligada representación topográfica del territorio, entre estos elementos se incluyen planos y perfiles de detalle de los castillos conquistados y vistas de las localidades sitiadas tomadas desde puntos distintos o en días sucesivos. Cada uno de estos elementos posee sus propias entradas en leyendas ciertamente extensas y no siempre compartimentadas (números, letras mayúsculas y minúsculas, y símbolos estandarizados) y, en el caso de los perfiles y las delineaciones topográficas y de obra nueva, escalas diferenciadas en varas castellanas. La meticulosidad con la que se trasladan distancias y ángulos implica, necesariamente, mediciones precisas a lo largo de varios días; las excelentes vistas figurativas que acompañan la cartografía propiamente dicha, una atención que no es posible en el fragor de los combates. Son planos hechos bajo la euforia de la victoria, en los que desaparece cualquier referencia a la presencia de las tropas carlistas. Son, en definitiva, pequeños testamentos del territorio conquistado, inventarios sucintos de las piezas cobradas, actas de la toma de posesión de los baluartes abandonados por el enemigo.

Aunque Fanti no pertenecía al Real Cuerpo de Ingenieros Militares, la formación académica que había recibido en Módena y la experiencia que adquirió en los trabajos de fortificación de Lyon, Brotteaux y El Bruc hicieron que, de facto, actuase como un miembro más de este colectivo. Por este motivo, en sus planos puede reconocerse la mayoría de las reglas cartográficas contenidas en las ordenanzas e instrucciones del Arma de Ingenieros de $1718,1757,1768$ y 1803. Estas disposiciones carecían de una normativa específica sobre 


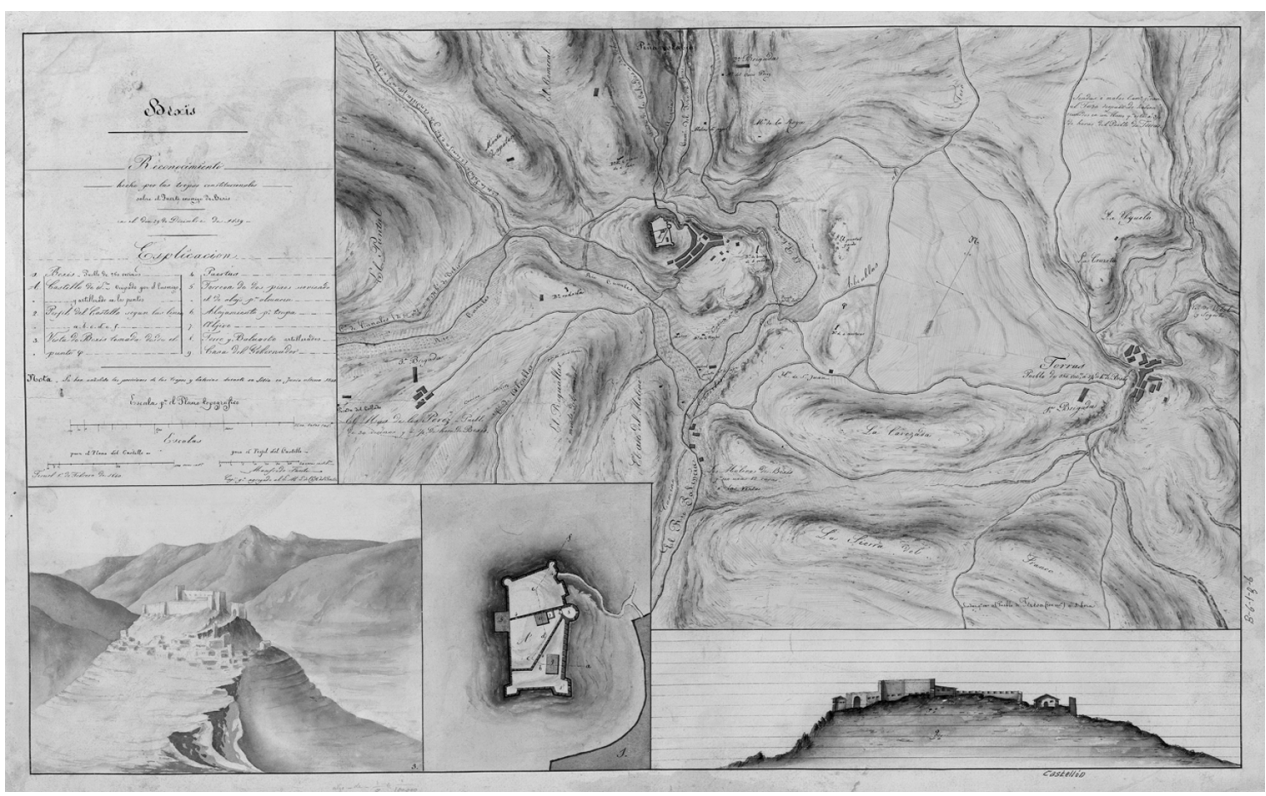

Fig. 5. M. Fanti, Bexís, 1840 (España, Ministerio de Defensa, Centro Geográfico del Ejército, Láminas históricas de la Región Valenciana, no 104). Pl. 4 del Cuadro 2.

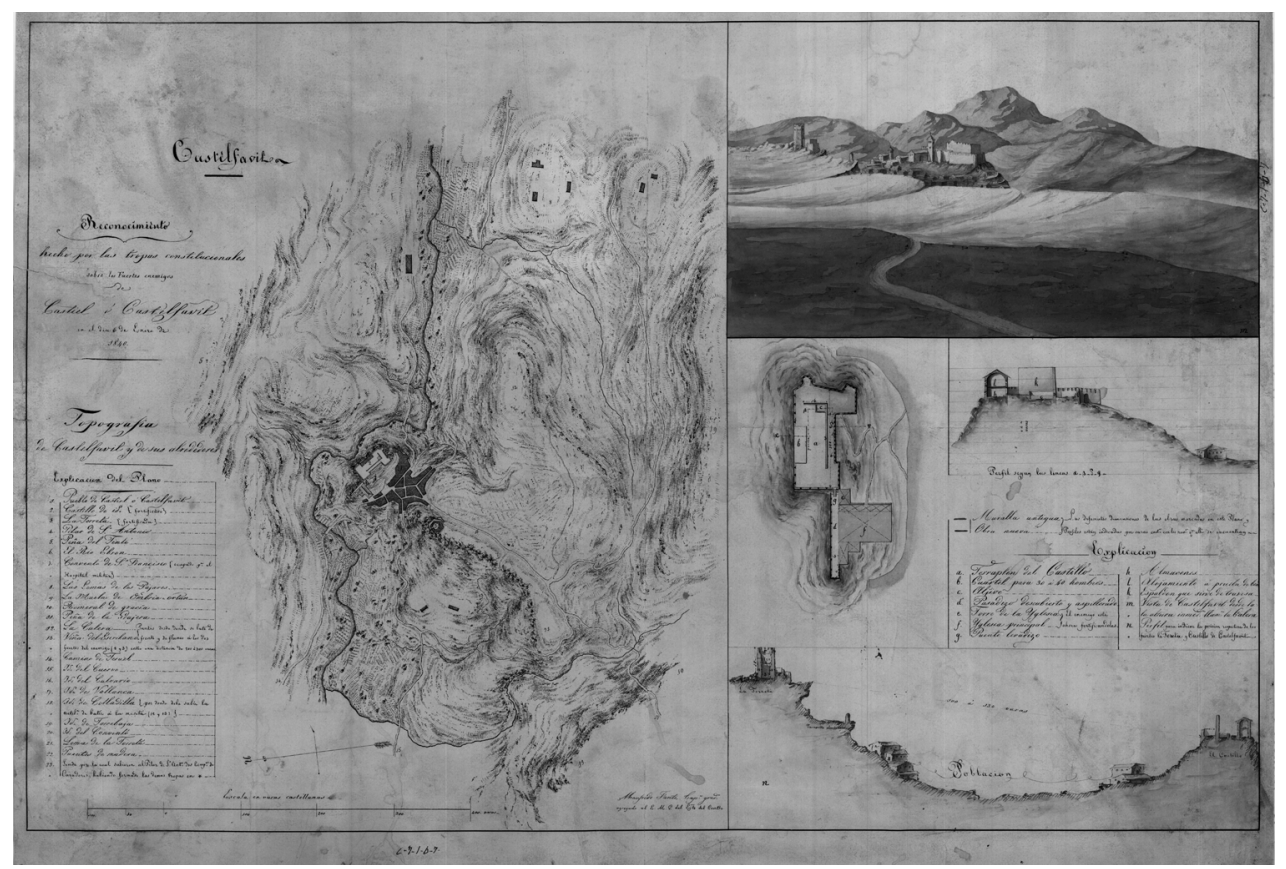

Fig. 6. M. Fanti, Castelfavit, 1840 (España, Ministerio de Defensa, Centro Geográfico del Ejército, Láminas históricas de la Región Valenciana, ${ }^{\circ}$ 205). Pl. 5 del Cuadro 2. 
aspectos fundamentales como el uso de un determinado sistema de proyección, la localización astronómica de los puntos de interés o la representación del relieve, pero, como hemos visto, establecían con total precisión las escalas, los formatos y los signos convencionales que debían utilizarse en mapas y planos. No es de extrañar, por lo tanto, que todos los que salieron de las manos de los ingenieros militares (incluyendo a Fanti) tuvieran una imagen de marca característica, definida por el uso de escalas diferenciadas para las partes topográfica y de castrametación, la atención privilegiada prestada a la red de caminos y cursos de agua, la obligada orientación mediante flecha o flor de lis, el uso de números y letras en una leyenda que se completaba con signos predeterminados o la plasmación detallada del territorio próximo a los objetivos militares y a las plazas habitadas.

\section{CONCLUSIÓN}

La cartografía española de la primera mitad del siglo XIX posee los rasgos propios de un fin de época, de un cruce de caminos. En el caso concreto de la referida a la Primera Guerra Carlista de la que dispuso el ejército liberal, objeto de este artículo, este carácter está plenamente justificado por el uso recurrente de la cartografía de base confeccionada durante la Guerra de la Independencia, claramente insuficiente para moverse en el territorio dominado por las partidas carlistas, y el retraso con el que se aprobó la formación del Cuerpo de Estado Mayor General del Ejército. En este sentido, la labor llevada a cabo por el Real Cuerpo de Ingenieros Militares no bastó para compensar el tiempo perdido durante el reinado de Fernando VII. La emergencia de la nueva cartografía habría de esperar a la batería de medidas puesta en práctica por el estado liberal, en las décadas de 1850 y 1860, con el objetivo de aproximar la cartografía española a la que se producía en esos momentos en Gran Bretaña y Francia. Sólo a partir de la publicación de la primera edición del Mapa Topográfico Nacional a escala 1:50.000 en 1875 puede hablarse de la existencia de una cartografía seriada en España (Nadal y Urteaga, 1990).

En este largo trayecto, el estudio del contexto en el que fueron realizados planos como los firmados por Manfredo Fanti puede ayudarnos a comprender la sorprendente capacidad de resistencia de una cartografía condenada a la desaparición. Fanti llegó a España en julio de 1835, con el objetivo de unirse como voluntario al ejército liberal que combatía la insurgencia legitimista, y no la abandonaría hasta 1848, cuando decidió regresar a Italia. Durante esta etapa crucial de su vida participó en las dos primeras guerras carlistas, especializándose, según dejó escrito en sus memorias, en la parte topográfica e histórica de la guerra (Piva, 1914; Spaggiari, 1965: 59). Su adscripción inicial al Estado Mayor General del Ejército, organismo que tenía encomendadas estas funciones desde 1838 junto al Depósito de la Guerra que le era anexo, fue posible gracias a su desenvoltura en las tareas cartográficas en el campo de batalla. Dibujante hábil, dotado de recursos y método, supo ganarse la confianza de sus superiores mientras les acompañaba en los momentos decisivos que pusieron fin a la Guerra de los Siete Años en el frente del Maestrazgo. Poco importa que la labor cartográfica consecuente fuera, vista su trayectoria posterior, un paréntesis en su carrera militar, un simple capítulo que le permitió iniciarla con fuerza antes de formar parte de la línea de mando del ejército isabelino y, más tarde, convertirse en un héroe nacional en Italia $^{12}$.

12 No conocemos ningún plano de Fanti de la Segunda Guerra Carlista. Tampoco existe ninguna referencia que nos indique que continuó esta labor en Italia. 
Lo auténticamente relevante para nosotros es que la obra cartográfica de Fanti constituye un ejemplo paradigmático de cómo se produjo la transición entre la cartografía moderna de autor y la cartografía de estado iniciada en España en la segunda mitad del siglo XIX. Así, junto a elementos como la firma reivindicativa, los títulos excesivos en su detalle, las notas anexas y explicativas de última hora o la persistencia de la figuración en vistas o caseríos habitados, encontramos en ella aquellos otros que definen la cartografía estandarizada a la que hoy estamos acostumbrados: las escalas ineludibles y diferenciadas en función del motivo de la representación, el uso predeterminado y con carga simbólica del color, las leyendas reducidas a letras y símbolos comunes o, en definitiva, el empleo inmediato y restringido de mapas y planos sin ánimo de trascendencia. Si los primeros nos retrotraen a la tradición de la cartografía demostrativa del siglo XVIII, estos últimos muestran cómo la generalización de las reglas que habrían de convertir a la cartografía en un lenguaje plenamente normalizado avanzaba de manera irreversible. La participación en este proceso de instituciones como el Real Cuerpo de Ingenieros Militares está más que demostrada.

\section{BIBLIOGRAFÍA}

ALBEAR, F.; RODRÍGUEZ, Á.; OSORIO, A. (1849): Colección de signos convencionales para la representación de los objetos en los planos y cartas, Madrid, Imprenta Real, $32 \mathrm{p}$.

ALONSO, M. Á. (1972): Aportación militar a la cartografía española en la historia contemporánea. Siglo XIX, Madrid, CSIC-Instituto de Geografía Aplicada, 382 p.

ALONSO, M. Á. (1982): "Cartografía militar española en la primera mitad del siglo XIX", Boletín de Información del Servicio Geográfico del Ejército, 52, pp. 7-52.

AUSEJO, E.; VELAMAZÁN, M. Á. (1989): "Los planes de estudio en la Academia de Ingenieros del Ejército de España en el siglo XIX”, Llull, 12, pp. 415-453.

BULlÓN, A. (1992): La Primera Guerra Carlista, Madrid, Actas, 758 pp.

CAPEL, H.; SÁNCHEZ, J. E.; MONCADA, O. (1988): De Palas a Minerva. La formación científica y la estructura institucional de los ingenieros militares en el siglo XVIII, Barcelona, SerbalCSIC, 390 pp.

CARANDINI, F. (1872): Manfredo Fanti, generale d'Armata. Sua vita, Verona, Stablimento Giuseppe Civelli, $481 \mathrm{pp}$.

CARIDAD, A. (2013): El ejército y las partidas carlistas en Valencia y Aragón (1833-1840), Valencia, Universitat de València, $364 \mathrm{pp}$.

CARRILlO, J. (2008): Caballeros de la Real Orden de San Fernando (Ingenieros), Madrid, Ministerio de Defensa, $216 \mathrm{pp}$.

Colección de las Leyes, Decretos y Declaraciones de las Cortes, y de los Reales Decretos, Órdenes, Resoluciones y Reglamentos Generales (...), desde $1^{\circ}$ de Enero hasta fin de Diciembre de 1838 (1839), Madrid, Imprenta Nacional, 746 pp.

CRAMPTON, J. W. y KRYGIER, J. (2006): “An introduction to critical cartography”, ACME: An International E-Journal for Critical Geographies, 4 (1), pp. 11-33.

CUERPO DE ESTADO MAYOR DEL EJÉRCITO (1883): Atlas Topográfico de la narración militar de la Guerra Carlista de 1869 a 1876, Madrid, Depósito de la Guerra, 420 pp. + 9 láminas.

EDNEY, M. H. (2007): "Recent Trends in the History of Cartography: A Selective, Annotated Bibliography to the English-Language Literature", Online Journal of the Map and Geography Round Table, American Library Association, Series B, 6.

Estado Militar de España. Año de 1839 (1839), Madrid, Imprenta Nacional, 168 pp. 
GALERA, M. (2000): "Guerra i cartografia a Catalunya. Segles XVII-XX”, en Galera, M., Montaner, M. C. y Rosselló, V. M. (eds.), La cartografia catalana, Barcelona, Institut Cartogràfic de Catalunya, pp. 119-195.

IZQUIERDO, S. (2004): "La cartografía de las Guerras Carlistas", en Bullón, A. (ed.), Las Guerras Carlistas, Madrid, Ministerio de Cultura, pp. 231-241.

MORAL, A. M. (2006): Las Guerras Carlistas, Madrid, Sílex, 402 pp.

MURO, J. I. (1991): "El Estado Mayor. La formación de un cuerpo facultativo encargado de la dirección de la guerra (1801-1841)", Revista de Historia Militar, vol. XXXV, nº 70, pp. 89-144.

MURO, J. I. (1993): El pensamiento militar sobre el territorio en la España contemporánea, Madrid, Ministerio de Defensa, $579+351$ pp.

MURO, J. I.; NADAL, F.; URTEAGA, L. (1996): Geografía, estadística y catastro en España. 1856-1870, Barcelona, Ediciones del Serbal, 275 pp.

NADAL, F.; URTEAGA, L., (1990): "Cartografía y Estado. Los mapas topográficos nacionales y la estadística territorial en el siglo XIX”, Geo-Crítica, 88.

Ordenanza que S. M. manda observar en el servicio del Real Cuerpo de Ingenieros (1803), Madrid, Imprenta Real, I, 294 pp.

PALADINI, Á. (1989): “Cartografía militar española de Indias”, Revista de Cultura Militar, 1, pp. $57-89$.

PIVA, G. (1914): Il carteggio del Generale Manfredo Fanti (1838-1865), Carpi, Tipografia Rossi, $55 \mathrm{pp}$.

PULVIRENTI, C. M. (2011): Il presagio spagnolo. Diplomazie e volontari italiani nella prima guerra carlista, Università degli Studi di Catania, Tesi di Dottorato, 377 pp.

RICCARDI, P. (1864): Cenni storici sull'istituto dei cadetti matematici pioneri di Modena, Modena, Zanichelli, $79 \mathrm{pp}$.

ROSSELLÓ, V. M. (2008): Cartografia històrica dels Països Catalans, València, Universitat de València-Institut d'Estudis Catalans, 402 pp.

SERVICIO GEOGRÁFICO DEL EJÉRCITO (1974): Cartoteca Histórica. Índice de Atlas Universales y Mapas y Planos Históricos de España, Madrid, Sección de Documentación, 268 pp.

SERVICIO GEOGRÁFICO DEL EJÉRCITO (1990): Cartoteca Histórica. Índice de Memorias e Itinerarios Descriptivos de España, Madrid, Sección de Documentación, 127 pp.

SPAGGIARI, E. (1939): "Legionari italiani in Spagna nel secolo scorso", Le Forze Armate, aprilemaggio, 1471-1472-1474.

SPAGGIARI, E. (1965): Manfredo Fanti e la Spagna, Modena, Tipografia Editrice Inmacolata Concezione, $134 \mathrm{pp}$. 